\title{
Electrospun Pectin-Polyhydroxybutyrate Nanofibers for Retinal Tissue Engineering
}

Siew Yin Chan, ${ }^{\dagger,}$ Benjamin Qi Yu Chan, ${ }^{\ddagger} \S \odot$ Zengping Liu, " Bhav Harshad Parikh, "Kangyi Zhang, Qianyu Lin, ${ }^{\ddagger, \S}$ Xinyi Su, $\|, \perp, \#, \nabla$ Dan Kai, ${ }^{\ddagger}$ Wee Sim Choo, ${ }^{*}, \dagger$ David James Young, ${ }^{*}, \uparrow,+, \bigcirc$

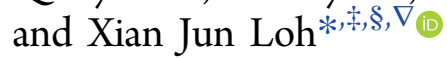

${ }^{\dagger}$ School of Science, Monash University Malaysia, Jalan Lagoon Selatan, 47500 Bandar Sunway, Selangor, Malaysia

${ }^{\ddagger}$ Institute of Materials Research and Engineering (IMRE), Agency for Science, Technology and Research (A*STAR), 2 Fusionopolis Way, Innovis, Singapore 138634, Singapore

${ }^{\S}$ Department of Materials Science and Engineering, National University of Singapore, 9 Engineering Drive 1, Singapore 117576, Singapore

"Department of Ophthalmology, Yong Loo Lin School of Medicine, National University of Singapore, 1E Kent Ridge Road, Singapore 119228, Singapore

${ }^{\perp}$ Institute of Molecular and Cell Biology (IMCB), Agency for Science, Technology and Research (A*STAR), 61 Biopolis Drive, Proteos, Singapore 138673, Singapore

\#Department of Ophthalmology, National University Hospital, 5 Lower Kent Ridge Road, Singapore 119074, Singapore

${ }^{\nabla}$ Singapore Eye Research Institute (SERI), 11 Third Hospital Avenue, Singapore 168751, Singapore

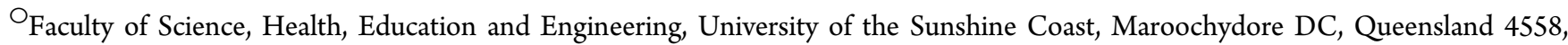
Australia

\section{Supporting Information}

ABSTRACT: Natural polysaccharide pectin has for the first time been grafted with polyhydroxybutyrate (PHB) via ring-opening polymerization of $\beta$-butyrolactone. This copolymer, pectin-polyhydroxybutyrate (pec-PHB), was blended with $\mathrm{PHB}$ in various proportions and electrospun to produce nanofibers that exhibited uniform and beadfree nanostructures, suggesting the miscibility of $\mathrm{PHB}$ and pec-PHB. These nanofiber blends exhibited reduced fiber diameters from 499 to $336-426 \mathrm{~nm}$ and water contact angles from 123.8 to $88.2^{\circ}$ on incorporation of pec-PHB. They also displayed 39-335\% enhancement of elongation at break relative to pristine $\mathrm{PHB}$ nanofibers. pec-PHB nanofibers were found to be noncytotoxic and biocompatible. Human retinal pigmented epithelium (ARPE-19) cells were seeded onto pristine $\mathrm{PHB}$ and pec-PHB nanofibers as scaffold and showed good proliferation. Higher proportions of pec-PHB (pec-PHB10 and pec-PHB20) yielded

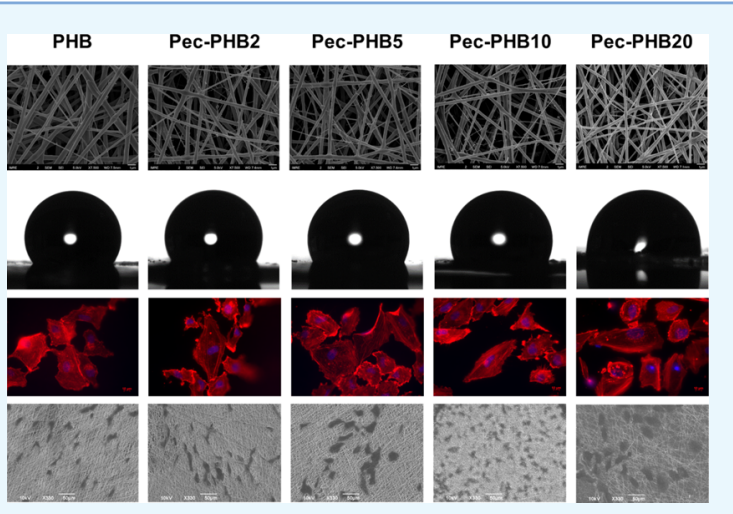
higher densities of cells with similar characteristics to normal RPE cells. We propose, therefore, that nanofibers of pec-PHB have significant potential as retinal tissue engineering scaffold materials.

\section{INTRODUCTION}

A rapidly expanding world population and concomitant deletion of resources in the postindustrial era has led to increasing research on the applications of sustainable materials, such as pectin, ${ }^{1-3}$ lignin, ${ }^{4-6}$ cellulose, ${ }^{7}$ and chitosan. ${ }^{8}$ One of the most abundant renewable polymers is pectin; a complex carbohydrate found in higher plants. Pectin consists mainly of galacturonic acid units joined by $\alpha-(1 \rightarrow 4)$ linkages. ${ }^{9}$ Commercial pectin is obtained by acid extraction from waste products by the food industry, such as apple pomace, citrus peel, and sugar beet pulp. It is widely used as a gelling agent, emulsifier, glazing agent, stabilizer, and thickener in food applications. ${ }^{1}$ Pectin's nontoxic, biodegradable, and biocompat- ible properties suggest potential as a biomaterial for use in personal care, pharmaceutical, and biomedical applications. ${ }^{1,9,10}$

The general insolubility of pectin in organic solvents stymies its application in the polymer field. ${ }^{2}$ Chemical modification is necessary to overcome this drawback, but most conventional chemical modifications take place in organic solvents, in which pectin is insoluble. Previous chemical modifications of pectin were mostly carried out in water and include methylation, ${ }^{11}$ acetylation, ${ }^{12}$ amidation, ${ }^{13}$ alkylation, ${ }^{14,15}$ quaternization, ${ }^{16}$

Received: October 19, 2017

Accepted: December 1, 2017

Published: December 14, 2017 


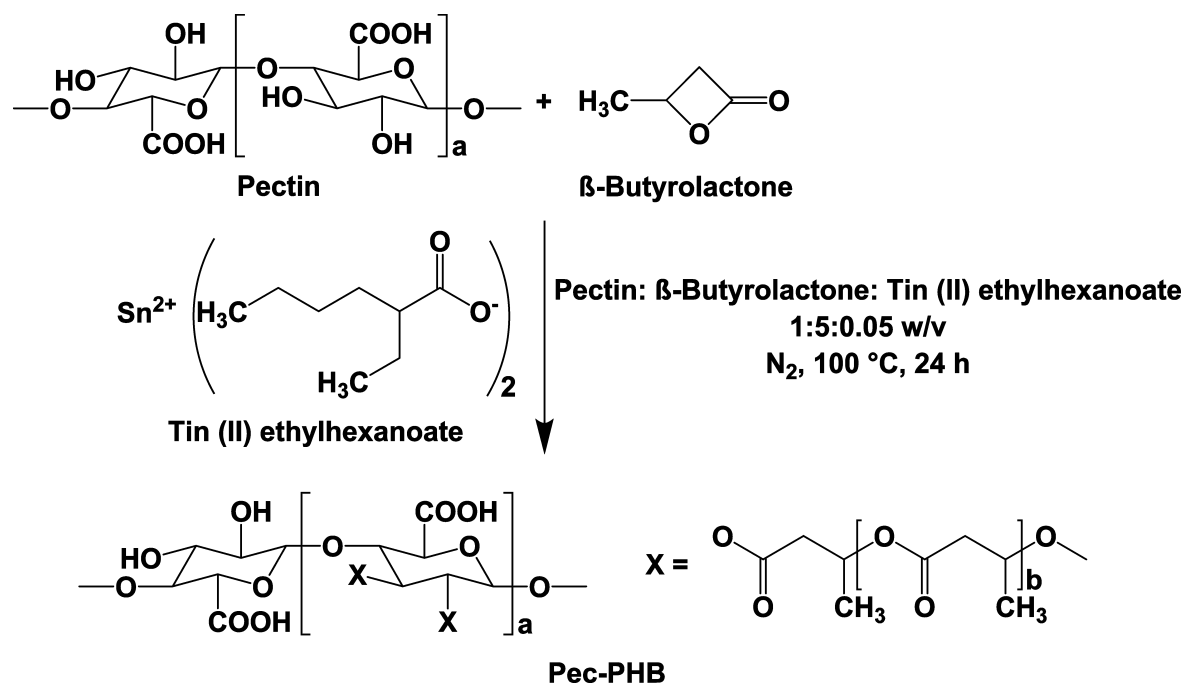

Figure 1. Ring-opening polymerization of $\beta$-butyrolactone using pectin as initiator to yield pec-PHB.

thiolation, ${ }^{17}$ sulfation, ${ }^{18}$ cross-linking, ${ }^{19}$ grafting, ${ }^{2}$ and depolymerization. $^{20,21}$ These pectin derivatives possessed improved physicochemical properties, including solubility, ${ }^{2}$ gelling ${ }^{2,11,15}$ and/or biological characteristics, ${ }^{13}$ such as anticoagulation ${ }^{18}$ and bioadhesion. ${ }^{17}$ In addition, new functionality, such as emulsifying and emulsion stabilizing, ${ }^{12,19}$ antimicrobial activity, ${ }^{16}$ and antioxidant properties, ${ }^{22}$ have been discovered. Herein, we report for the first time the grafting of pectin with $\mathrm{PHB}$ via solventless ring-opening polymerization (ROP) of $\beta$-butyrolactone to afford pectin-polyhydroxybutyrate (pec$\mathrm{PHB})$, which is soluble in organic solvents.

Polyhydroxybutyrate (PHB) is a renewable, biodegradable, and biocompatible polymer commonly utilized as a biomaterial. $^{23-27}$ However, the application of PHB in the biomedical field has been hampered by its hydrophobicity, brittleness, and slow rate of biodegradation. ${ }^{28}$ There has, therefore, been increasing research on blending or grafting $\mathrm{PHB}$ with natural polymers, including alginate, ${ }^{29}$ carrageenan, $^{30}$ cellulose, $^{31}$ and chitosan. ${ }^{32}$ The greater hydrophilicity and biodegradability of pectin could potentially overcome the limitations of $\mathrm{PHB}$, generating a copolymer with more suitable physical and chemical properties than each component polymer.

In plants, pectin constitutes the matrix in which other components, such as cellulose microfibrils, are embedded and has been shown to have important roles in regulating the biological and mechanical behavior of cell walls. ${ }^{1,9,33-35}$ Inspired by this structural function of pectin in plants, we have utilized our pectin copolymer as a filler to be blended with $\mathrm{PHB}$ for electrospinning into nanofibers. Electrospinning is a technique that utilizes electrostatic forces to produce fibers with diameters in the range of micrometers to nanometers. ${ }^{5,36}$ Bulk materials can be electrospun to fibers with a porous, threedimensional interconnected network structure. ${ }^{37}$ These porous matrices have high specific areas, and their nanoscale architectures may be used to mimic morphological features of the native extracellular matrix (ECM) for biomedical applications. ${ }^{38-43}$ Recent reports have demonstrated that nanofibers are promising candidates for tissue engineering scaffolds. ${ }^{44,45}$

Ocular disorders, such as retinal degeneration, can cause impaired vision and total blindness. Transplantation of retinal cells is a feasible approach to alleviate these diseases. Achieving good viabilities, differentiation, and integration of retinal epithelial cells, however, remains a challenge. ${ }^{46}$ Recent reports have proposed the possibility of seeding retinal cells onto soft, polymeric scaffolds, ${ }^{47,48}$ which can be made of natural or synthetic polymers, such as collagen and poly(lactic acid), respectively. ${ }^{49}$ Natural polymers are able to facilitate cell signaling and have good biodegradability, but they have drawbacks such as structure heterogeneity and difficulty in functionalization. $^{50}$ Synthetic polymers, by comparison, are generally mechanically stronger, but lack biological functionality. ${ }^{51}$ Copolymers combining the advantages of both could have potential for constructing soft frameworks for cell growth. Our electrospun pec-PHB nanofibers have been evaluated for their potential as scaffolds for retinal tissue engineering in terms of their topographical, thermal, and mechanical properties. We also report their biocompatibility and capacity to support the proliferation and growth of seeded human retinal pigmented epithelium (ARPE-19) cells.

\section{RESULTS AND DISCUSSION}

2.1. Synthesis and Characterization of pec-PHB Copolymer. pec-PHB was synthesized from $\beta$-butyrolactone monomer using pectin as initiator by in situ ROP. Polymerization was carried out in bulk and initiated by the pectin hydroxyl groups in the presence of catalyst tin(II) 2ethylhexanoate (Figure 1). ${ }^{1} \mathrm{H}$ NMR spectroscopy was performed on pectin $\left(\mathrm{D}_{2} \mathrm{O}\right)$, PHB $\left(\mathrm{CDCl}_{3}\right)$, and pec-PHB $\left(\mathrm{CDCl}_{3}\right)$ (Figures $\mathrm{S} 1-\mathrm{S} 3$ ). Pectin cannot be dissolved in organic solvents and thus pectin's spectra in $\mathrm{CDCl}_{3}$ are not available. The spectra of pec-PHB contained peaks characteristic of PHB and pectin. Broad proton signals were observed between 3 and $4 \mathrm{ppm}$ that are attributed to the pectin moiety, supported by previous reports of the ${ }^{1} \mathrm{H}$ NMR spectra of modified (persilylated) cyclodextrins in $\mathrm{CDCl}_{3}$, which concluded that almost all of the carbohydrate ring protons occurred between 3 and 5 ppm in broad signals. ${ }^{52}$ To further verify the successful grafting of $\mathrm{PHB}$ on pectin, Fourier transform infrared (FTIR) spectra of pec-PHB displayed absorption characteristics of both pectin and PHB (Figure 2). The spectrum of pec-PHB contained a hydrogen-bonded $\mathrm{O}-\mathrm{H}$ absorption at $3450 \mathrm{~cm}^{-1}$, a fingerprint absorption at $1010 \mathrm{~cm}^{-1}$ that can be assigned to pectin, ${ }^{53-55}$ and $\mathrm{C}-\mathrm{H}$ absorptions 


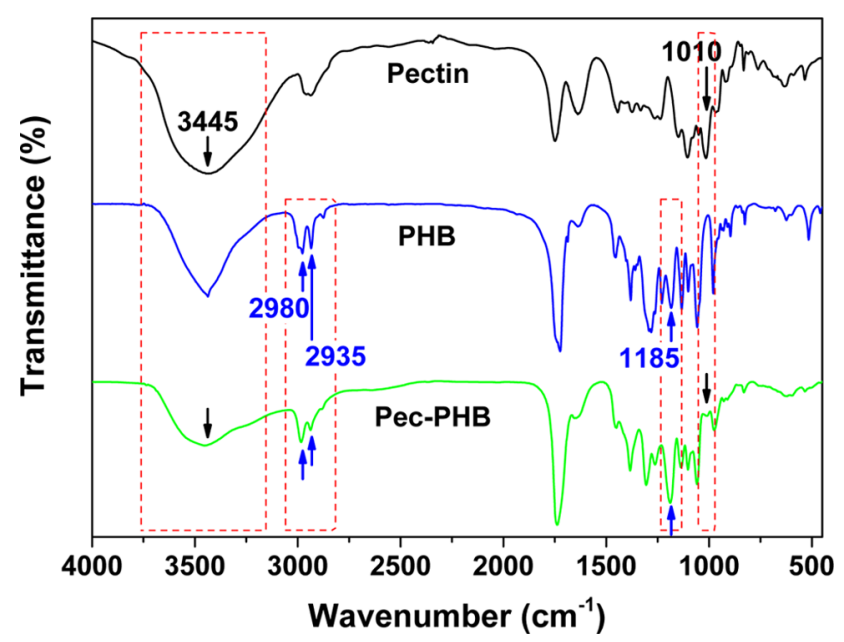

Figure 2. FTIR spectra of the precursors (pectin and PHB) and copolymer pec-PHB.

$\left(\mathrm{CH}_{2}\right.$ and $\left.\mathrm{CH}_{3}\right)$ at around $2950 \mathrm{~cm}^{-1}$, together with $\mathrm{C}-\mathrm{O}-\mathrm{C}$ vibrations at $1185 \mathrm{~cm}^{-1}$ that match $\mathrm{PHB} .{ }^{36,57}$

Thermogravimetric analysis (TGA) revealed that grafting $\mathrm{PHB}$ on pectin causes a reduction in the degradation temperature $\left(T_{\mathrm{d}}\right)$ of pec-PHB $\left(246.26{ }^{\circ} \mathrm{C}\right)$ relative to that of pristine PHB $\left(288.44^{\circ} \mathrm{C}\right)$. Despite reduced thermal stability, pec-PHB was stable up to $240{ }^{\circ} \mathrm{C}$. The presence of a single decomposition step represents the successful grafting of $\mathrm{PHB}$ on pectin. Like pectin, pec-PHB has a high residue content (15.31\%) (Table S1), possibly due to the presence of sodium and potassium salts of uronic acid groups. ${ }^{58,59}$

PHB is a semicrystalline polymer with melting temperature $\left(T_{\mathrm{m}}\right)$ of $160.98^{\circ} \mathrm{C}$ and glass-transition temperature $\left(T_{\mathrm{g}}\right)$ of 8.69 ${ }^{\circ} \mathrm{C}$. Differential scanning calorimetry (DSC) analysis revealed that pec-PHB is fully amorphous with the disappearance of the melting peak (Figure S4). The amorphous property of pec$\mathrm{PHB}$ also suggests that the polymerized $\mathrm{PHB}$ chains on the pectin backbone are most likely in an atactic configuration. ${ }^{60}$ This hypothesis is further supported by the stronger intensity of the FTIR band at $1185 \mathrm{~cm}^{-1}$ in pec-PHB, which is sensitive to the amorphous state of PHB (Figure 2). ${ }^{57}$ The presence of a single $T_{\mathrm{g}}$ for pec-PHB further indicates the successful grafting of PHB on pectin (Figure S4). Compared to pristine pectin and $\mathrm{PHB}$, the $T_{\mathrm{g}}$ of the copolymer was lower $\left(-15.41^{\circ} \mathrm{C}\right)$ (Table $\mathrm{S} 1$ ), indicating its increased rubbery nature and improved chain conformation flexibility and mobility, even at temperatures lower than $0{ }^{\circ} \mathrm{C}$. ${ }^{61}$ TGA and DSC therefore confirmed the successful grafting of $\mathrm{PHB}$ on the pectin backbone.

2.2. Electrospinning of $\mathrm{PHB} /$ pec-PHB Fibers. Through grafting with $\mathrm{PHB}$, pectin in pec-PHB was rendered soluble in organic solvents chloroform and 1,1,1,3,3,3-hexafluoro-2propanol and could be blended with $\mathrm{PHB}$ for further engineering of porous surfaces. A series of $\mathrm{PHB} / \mathrm{pec}-\mathrm{PHB}$ fibers with different mass ratios were prepared (Table 1). Pectin content increased with increasing pec-PHB content in the blend. The influence of pectin composition on the morphology and fiber diameters of $\mathrm{PHB} /$ pec-PHB are summarized in Figure 3. The fibers exhibited uniform and bead-free nanostructures, suggesting that $\mathrm{PHB}$ and pec-PHB copolymers were miscible on the nanoscale. Scanning electron microscopy (SEM) images revealed a three-dimensional porous structure with a microenvironment mimicking the geometry of the extracellular matrix (ECM). The incorporation of pectin copolymers was
Table 1. Samples of PHB and pec-PHB (w/w) Used To Prepare Solution Mixtures with a Preset Total Concentration of $3 \%(\mathrm{w} / \mathrm{v})$ for Electrospinning

\begin{tabular}{ccc} 
& \multicolumn{2}{c}{$\begin{array}{c}\text { mass ratio of PHB and pec-PHB } \\
(\text { wt } \%) \text { with preset total concentration } \\
\text { of 3\% (w/v) }\end{array}$} \\
\cline { 2 - 3 } name of electrospun fiber & PHB & pec-PHB \\
pec-PHB2 & 98 & 2 \\
pec-PHB5 & 95 & 5 \\
pec-PHB10 & 90 & 10 \\
pec-PHB20 & 80 & 20 \\
\hline
\end{tabular}

observed to decrease the fiber diameters by up to $32.7 \%$ from $499 \pm 96 \mathrm{~nm}$, with blends of higher pectin composition affording thinner fibers. The fiber diameters of pec-PHB nanofibers were found to be within the range of structural extracellular matrix (ECM) fibrous proteins, which are from 50 to $500 \mathrm{~nm},{ }^{62}$ rendering pec-PHB nanofibers ideal candidates for tissue engineering.

2.3. Hydrophobicity of $\mathrm{PHB} /$ pec-PHB Nanofibers. Water contact angles of the $\mathrm{PHB} / \mathrm{pec}-\mathrm{PHB}$ nanofibers were determined to evaluate the hydrophobicity of the nanostructured surfaces. PHB nanofibers exhibited a water contact angle of $123.8 \pm 1.3^{\circ}$ (Figure 4 ), and the addition of pec-PHB copolymers enhanced the hydrophilicity of the nanofibers, inversely correlated to pec-PHB composition. pec-PHB20 was found to be quite hydrophilic, with a water contact angle of $88.2 \pm 1.2^{\circ}$. This reduction in the hydrophobicity of the nanofibers is presumably due to extra hydrogen bonding between water and the hydroxy groups of the incorporated pectin. Therefore, the hydrophobicity of PHB can be tuned by pec-PHB to meet the specific requirements of different applications. In the case of tissue engineering, the fibers need to maintain a suitable hydrophobic to hydrophilic ratio that enables both cell adhesion and resident cell hydration. ${ }^{63}$

2.4. Thermal Properties of PHB/pec-PHB Nanofibers. TGA revealed single-step decomposition of pec-PHB nanofibers, indicating miscibility between pec-PHB and PHB. Incorporating pec-PHB did not have a large effect on the thermal stability of $\mathrm{PHB} / \mathrm{pec}-\mathrm{PHB}$ nanofibers, which can withstand temperatures up to $240{ }^{\circ} \mathrm{C}$. The residue percentages of the pec-PHB nanofibers directly correlated with the composition of pec-PHB (Table 2), presumably due to the high residue content of pec-PHB (Table S1).

DSC measurements revealed a single $T_{\mathrm{g}}$ for pec-PHB nanofibers (Table 2), confirming the miscibility of pec-PHB and PHB. ${ }^{64}$ The $T_{\mathrm{g}}$ and cold crystallization temperature $\left(T_{\mathrm{cc}}\right)$ of pec-PHB nanofibers were slightly increased relative to pristine PHB (0.07 and $36.32{ }^{\circ} \mathrm{C}$, respectively) and inversely correlated to the composition of pec-PHB (Table 2). Degree of crystallinity was also inversely correlated with pectin content (Table 2). Compared to pristine PHB (50.81\%), all pec-PHB nanofibers exhibited lower degrees of crystallinity, excluding pec-PHB2 (53.21\%). The incorporation of up to $2 \%$ of amorphous pec-PHB allows the blend to be rearranged to a molecular conformation with increased intermolecular cohesive forces, ${ }^{65}$ favoring crystallization and thus a higher degree of crystallinity $(53.21 \%)$ and $T_{\mathrm{g}}\left(6.76{ }^{\circ} \mathrm{C}\right)$. There was no $T_{\mathrm{cc}}$ observed for pec-PHB2, confirming the stable molecular orientation of the blend. ${ }^{66}$ Further increase in pec-PHB content progressively disperses the $\mathrm{PHB}$ chains, increasing segmental mobility and hindering the crystallization process, and thus 


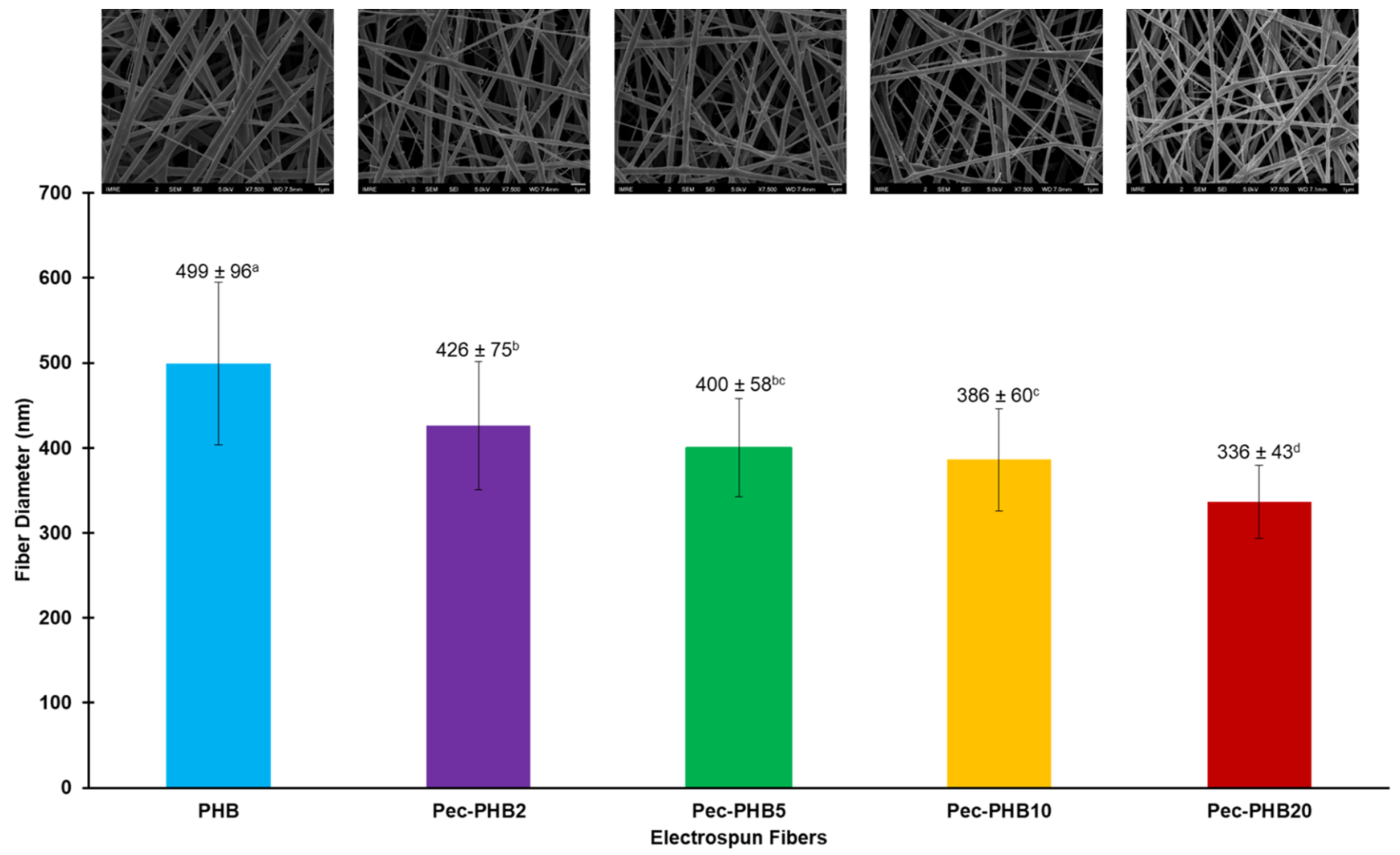

Figure 3. SEM images $(7500 \times)$ of the electrospun fibers (PHB, pec-PHB2, pec-PHB5, pec-PHB10, pec-PHB20) and their respective fiber diameters. Values plotted are means \pm standard deviations, with three replicates taken per data point. ${ }^{\text {abcd }}$ Values with different superscript letters are significantly different $(p<0.05)$.

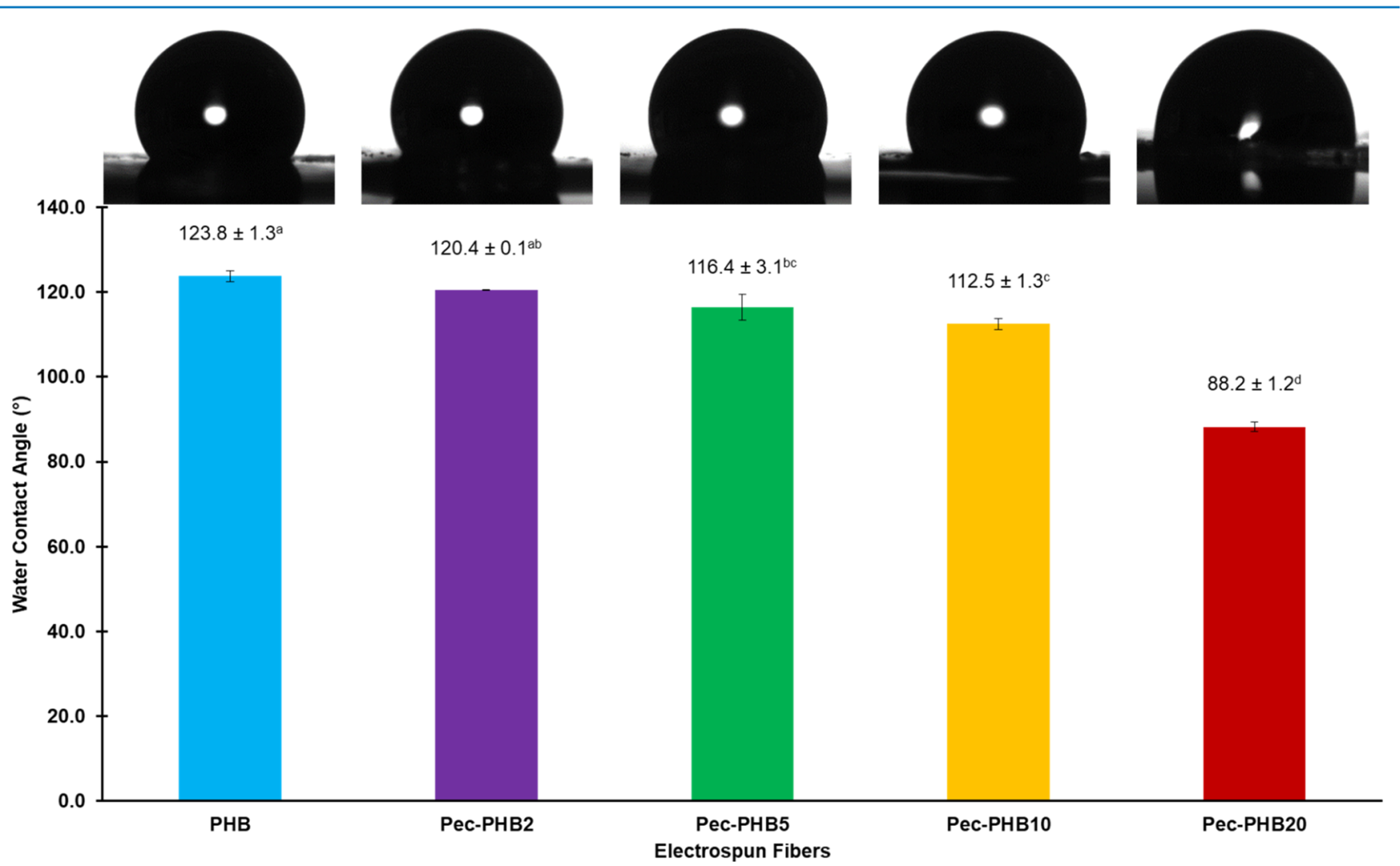

Figure 4. Water contact angles of electrospun fibers: PHB, pec-PHB2, pec-PHB5, pec-PHB10, and pec-PHB20. Values plotted are means \pm standard deviations, with three replicates taken per data point. ${ }^{\text {abcd }}$ Values with different superscript letters are significantly different $(p<0.05)$. 
Table 2. Thermal Properties of Electrospun Fibers: PHB, pec-PHB2, pec-PHB5, pec-PHB10, and pec-PHB20

\begin{tabular}{|c|c|c|c|c|c|c|c|c|}
\hline $\begin{array}{l}\text { electrospun } \\
\text { fibers }\end{array}$ & $\begin{array}{c}\text { thermal } \\
\text { decomposition } \\
\text { temperature, } T_{\mathrm{d}}{ }^{a} \\
\left({ }^{\circ} \mathrm{C}\right)\end{array}$ & $\begin{array}{l}\text { residue }^{b} \\
(\%)\end{array}$ & $\begin{array}{c}\text { glass-transition } \\
\text { temperature, } T_{\mathrm{g}}{ }^{c} \\
\left({ }^{\circ} \mathrm{C}\right)\end{array}$ & $\begin{array}{c}\text { cold crystallization } \\
\text { temperature, } T_{\mathrm{cc}}{ }^{c} \\
\left({ }^{\circ} \mathrm{C}\right)\end{array}$ & $\begin{array}{l}\text { heat of cold } \\
\text { crystallization, } \\
\Delta H_{\mathrm{cc}}{ }^{c}\left(\mathrm{~J} \mathrm{~g}^{-1}\right)\end{array}$ & $\begin{array}{c}\text { melting } \\
\text { temperature, } \\
T_{\mathrm{m}}{ }_{c}\left({ }^{\circ} \mathrm{C}\right)\end{array}$ & $\begin{array}{c}\text { heat of } \\
\text { melting, } \\
\Delta H_{\mathrm{m}}{ }^{c}\left(\mathrm{~J} \mathrm{~g}^{-1}\right)\end{array}$ & $\begin{array}{c}\text { degree of } \\
\text { crystallinity, } \\
X_{\mathrm{c}}^{d}(\%)\end{array}$ \\
\hline PHB & 247.75 & 0.98 & 0.07 & 36.32 & 3.34 & 149.63 & 77.52 & 50.81 \\
\hline pec-PHB2 & 242.76 & 1.30 & 6.76 & & & 161.00 & 79.27 & 53.21 \\
\hline pec-PHB5 & 250.68 & 1.47 & 3.07 & 41.57 & 1.77 & 161.20 & 77.97 & 49.40 \\
\hline pec-PHB10 & 257.40 & 1.86 & 2.22 & 40.45 & 1.97 & 158.85 & 72.93 & 43.77 \\
\hline pec-РНВ20 & 247.27 & 3.13 & 0.14 & 37.96 & 5.35 & 158.06 & 68.89 & 34.82 \\
\hline
\end{tabular}

${ }^{a} T_{\mathrm{d}}$ is defined as the temperature at which the mass of the sample has a $5 \%$ weight loss, determined by TGA. ${ }^{b}$ Residue is defined as the mass percentage of the sample at $500{ }^{\circ} \mathrm{C}$, determined from TGA. ${ }^{c} T_{\mathrm{g}}, T_{\mathrm{cc}} \Delta H_{\mathrm{cc}} T_{\mathrm{m}}$, and $\Delta H_{\mathrm{m}}$ were deduced from the second heating curve by DSC. $T_{\mathrm{m}}$ was taken as peak maxima. $\Delta H_{\mathrm{m}}$ and $\Delta H_{\mathrm{cc}}$ were determined from the endothermic melting peak and exothermic cold crystallization peak, respectively. ${ }^{d} X_{\mathrm{c}}$ was calculated using the following equation

$$
X_{\mathrm{c}}=\frac{\Delta H_{\mathrm{m}}-\Delta H_{\mathrm{c}}}{\Delta H_{\mathrm{m}}^{\mathrm{O}}} \times 100 \%
$$

where $\Delta H_{\mathrm{m}}^{\mathrm{O}}$ is a reference value, which represents the heat of melting for $100 \%$ crystalline $\mathrm{PHB}, 146 \mathrm{~J} \mathrm{~g}^{-1} \cdot{ }^{69} X_{\mathrm{c}}$ values were normalized based on the mass percentage of PHB segments in the fibers: $100 \%$ for PHB, $98 \%$ for pec-PHB2, $95 \%$ for pec-PHB5, $90 \%$ for pec-PHB10, and $80 \%$ for pecPHB20.

lowers the degree of crystallinity, $T_{\mathrm{g}}$, and $T_{\mathrm{cc}}$. Multiple melting peaks for $\mathrm{PHB}$ is a common phenomenon and has been explained by melting, recrystallization, and remelting of crystals with different lamellar thicknesses and/or structures. ${ }^{67}$ Melting peaks were gradually convoluted with increasing composition of pec-PHB (Figure 5), suggesting the nanofibers with increasing pec-PHB content resulted in more metastable crystals than ordered crystals. $^{68}$

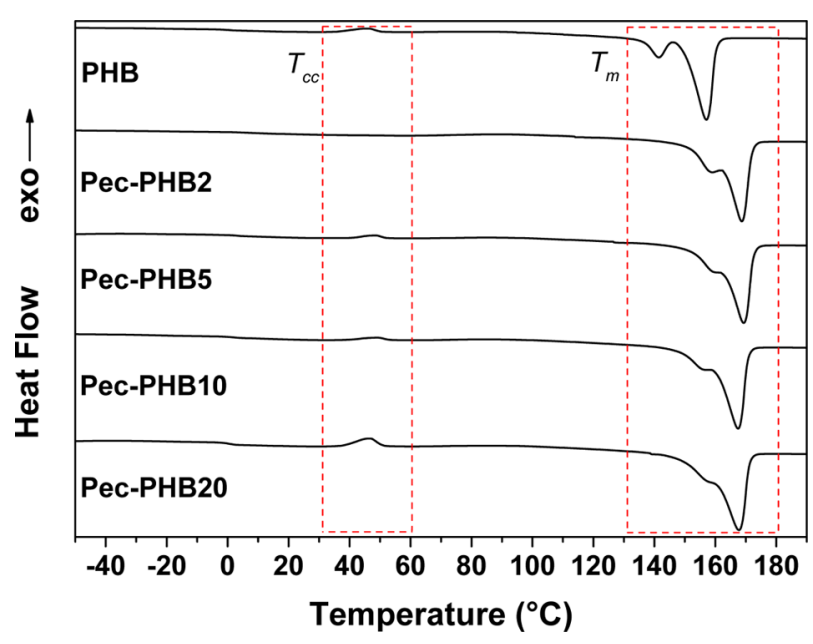

Figure 5. DSC curves of the electrospun fibers: $\mathrm{PHB}$, pec-PHB2, pecPHB5, pec-PHB10, and pec-PHB20.

2.5. Mechanical Properties of PHB/pec-PHB Nanofibers. Tensile tests were carried out at room temperature to evaluate the mechanical properties of pec-PHB nanofibers compared to pristine $\mathrm{PHB}$ nanofibers. PHB nanofibers displayed a Young's modulus of $0.15 \pm 0.01 \mathrm{GPa}$, ultimate tensile stress (UTS) of $4.72 \pm 0.71 \mathrm{MPa}$, and elongation at break $\left(\varepsilon_{\mathrm{b}}\right)$ of $5.12 \pm 0.14 \%$. The proportion of pec-PHB is inversely correlated with Young's modulus, UTS, and elongation at break (Table 3). pec-PHB2 displayed the best mechanical properties with $153 \%$ increase in Young's modulus, $165 \%$ increase in UTS, and 335\% enhancement in elongation at break. The next best was pec-PHB5, which had a Young's modulus comparable to pristine PHB, $131 \%$ increase in UTS,
Table 3. Mechanical Properties of Electrospun Fibers: PHB, pec-PHB2, pec-PHB5, pec-PHB10, and pec-PHB20 ${ }^{a}$

\begin{tabular}{lccr}
$\begin{array}{c}\text { electrospun } \\
\text { fibers }\end{array}$ & $\begin{array}{c}\text { Young's } \\
\text { modulus (GPa) }\end{array}$ & $\begin{array}{c}\text { ultimate tensile stress, } \\
\text { UTS (MPa) }\end{array}$ & $\begin{array}{r}\text { elongation at } \\
\text { break, } \varepsilon_{\mathrm{b}}(\%)\end{array}$ \\
\hline PHB & $0.15 \pm 0.00^{\mathrm{a}}$ & $4.72 \pm 0.71^{\mathrm{a}}$ & $5.12 \pm 0.14^{\mathrm{a}}$ \\
pec-PHB2 & $0.23 \pm 0.01^{\mathrm{b}}$ & $7.80 \pm 0.16^{\mathrm{b}}$ & $22.28 \pm 1.63^{\mathrm{b}}$ \\
pec-PHB5 & $0.15 \pm 0.00^{\mathrm{a}}$ & $6.16 \pm 0.35^{\mathrm{c}}$ & $12.08 \pm 0.38^{\mathrm{c}}$ \\
pec-PHB10 & $0.11 \pm 0.00^{\mathrm{c}}$ & $4.27 \pm 0.14^{\mathrm{a}}$ & $8.86 \pm 1.34^{\mathrm{d}}$ \\
pec-PHB20 & $0.08 \pm 0.01^{\mathrm{c}}$ & $3.03 \pm 0.04^{\mathrm{d}}$ & $7.11 \pm 0.67^{\mathrm{ad}}$
\end{tabular}

${ }^{a}$ Values are means \pm standard deviations, with three replicates taken per data point. ${ }^{\text {abcd }}$ Values within the column with different superscript letters are significantly different $(p<0.05)$.

and $236 \%$ enhancement in elongation at break. These results show that pec-PHB2 was stiffer than pristine $\mathrm{PHB}$ nanofibers and that pec-PHB5 had a similar stiffness to the latter. This is attributed to increased or similar degrees of crystallinity. ${ }^{70}$ Further increases of pec-PHB content (above $10 \mathrm{wt} \%$ ) reduced the Young's modulus and UTS of the nanofibers, corresponding to reduced degrees of crystallinity in pec-PHB10 and pecPHB20. These results demonstrated that nanofibers with higher composition of pec-PHB (above $10 \mathrm{wt} \%$ ) were less stiff and ductile compared to pristine PHB. Unlike typical fibers, which display trade-offs between stiffness and ductility, ${ }^{66}$ pec-PHB nanofibers were ductile and possessed a 139-335\% enhancement in elongation at break. pec-PHB2 and pec-PHB5 nanofibers are tougher than pristine $\mathrm{PHB}$, presumably due to the stable molecular orientation of these blends. ${ }^{66}$

2.6. ARPE-19 Cell Attachment and Proliferation. pecPHB nanofibers were found to be biodegradable, noncytotoxic, and biocompatible (Figures S5 and S6). We further explored the potential of pec-PHB nanofibers in retinal tissue engineering by studying the attachment and proliferation of ARPE-19 cells on the nanofibers.

Retinal pigment epithelium (RPE) is a layer of tissue from the back of the eye. ${ }^{71}$ RPE plays many complex roles in the eyes, and its degeneration is related to ocular disorders, such as retinitis pigmentosa, that can lead to vision blindness. ${ }^{71,72}$ As RPE cells are mostly nonproliferative, repair, and regeneration of the damaged tissue is nearly impossible. ${ }^{73}$ One possible solution is to culture RPE cells in vitro and induce them to 


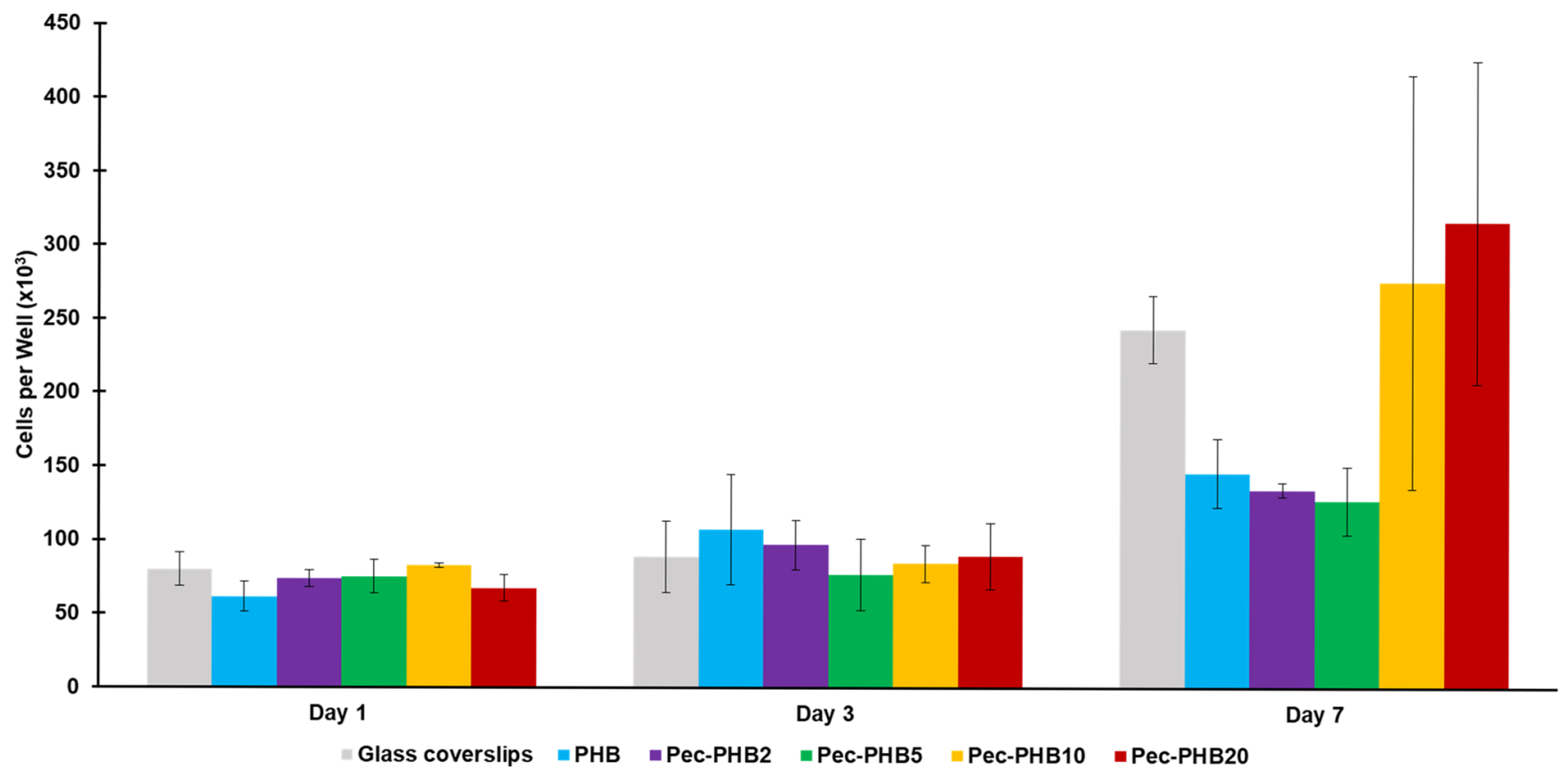

Figure 6. MTT assay indicated comparable cell attachment densities on all groups on days 1 and 3 . Values plotted are means \pm standard deviations, with three replicates taken per data point. One-way ANOVA (Tukey post hoc test) indicated that there was no significant difference between any groups.

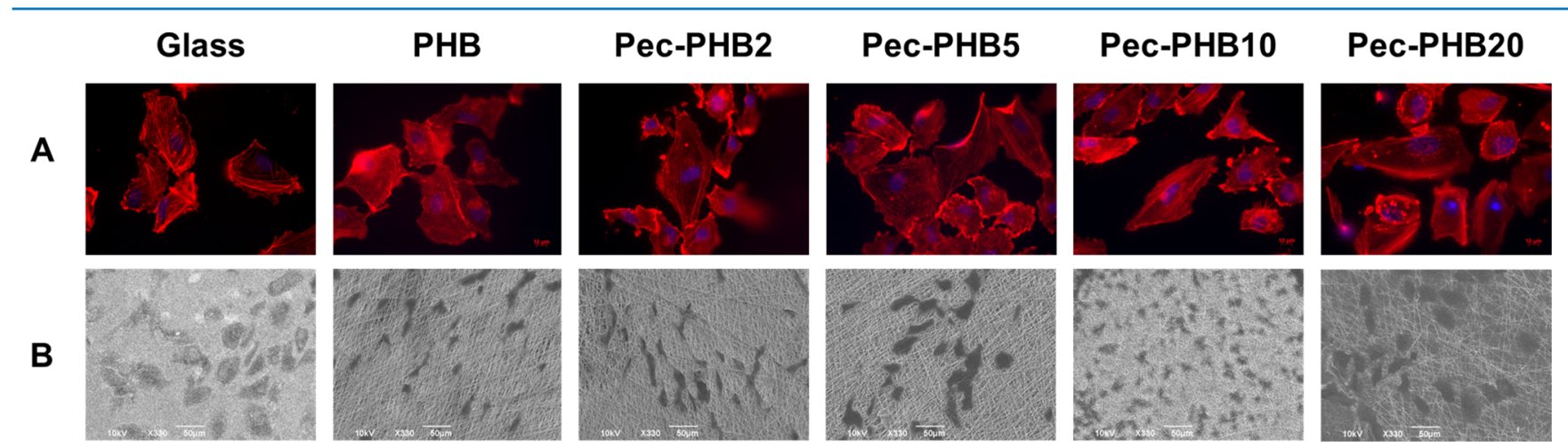

Figure 7. (A) Immunofluorescence images of ARPE-19 cells on different PHB nanofiber scaffolds stained with rhodamine phalloidin (red) to label F-actin and 4',6-diamidino-2-phenylindole (DAPI) to label nuclei; the scale bar is $10 \mu \mathrm{m}$. (B) SEM images (330X) of proliferating ARPE-19 cells on PHB scaffolds $24 \mathrm{~h}$ after seeding.

reenter the eye's medium in their glycolytic metabolism stage, during which proliferation, migration, and differentiation are possible. $^{71,72}$

One of the most commonly used RPE cell lines is ARPE-19, which displays similar cell morphology and gene expression to native human RPE cells. ${ }^{74}$ ARPE-19 cells were seeded at a density of $1.00 \times 10^{4}$ cells $\mathrm{cm}^{-2}$ onto $\mathrm{PHB}$ and pec-PHB nanofibers as scaffolds and glass coverslips (as control) in a 24well plate. Quantification of cell proliferation using an 3-(4,5dimethylthiazol-2-yl)-2,5-diphenyltetrazolium bromide (MTT) assay revealed that growth of ARPE-19 cells on day $1((72.11 \pm$ $\left.7.50) \times 10^{3}\right)$ and day $3\left((90.85 \pm 22.63) \times 10^{3}\right)$ after seeding was comparable among all five nanofibers (Figure 6). There was a significant difference in cell growth on day 7 between the nanofibers as determined by one-way analysis of variance (ANOVA) at the $p<0.05$ level $[F(4,10)=3.625, p=0.045]$. Cell density on pec-PHB10 and pec-PHB20 was higher relative to the other polymer blends. Apart from higher pectin content, which confers biocompatibility, ${ }^{50}$ the nanofibers of pec-PHB 10 and pec-PHB20 were smaller in diameter compared to the others. It has previously been demonstrated that cell viability and proliferation is highest with thinner, randomly aligned fibers. ${ }^{75}$ The reduction in crystallinity achieved with our pecPHB nanofibers is also important for cell attachment and proliferation. ${ }^{76}$ Crystallinity had been shown to decrease cell viability and proliferation on randomly aligned fibers. ${ }^{77}$

The expression of F-actin, which is associated with cell junctions, was assessed using rhodamine phalloidin $24 \mathrm{~h}$ after seeding (Figure 7A). The presence and distribution of F-actin was consistent with the pattern of F-actin expression in cells seeded on glass. This indicates that ARPE-19 cells had successfully adhered to the different scaffolds and were actively proliferating in pristine $\mathrm{PHB}$ and pec-PHB nanofibers. SEM analysis was performed to observe the morphology, adhesion, and proliferation of ARPE-19 cells (Figure 7B). SEM images were taken 1 day post seeding and revealed differences in morphology between the nanofibers. Cells on PHB, pec-PHB2, and pec-PHB5 did not retain the polygonal morphology as distinctively seen on glass. ARPE-19 cells on PHB10 and 
PHB20 were more rounded and localized, similar to the characteristic of normal RPE cells.

\section{CONCLUSIONS}

pec-PHB copolymer was successfully synthesized via ROP in bulk using pectin as initiator. Solubility in organic solvents was achieved by grafting $\mathrm{PHB}$ onto pectin. pec-PHB was blended with $\mathrm{PHB}$, and nanofibers produced by electrospinning were found to be of finer fiber morphologies with enhanced hydrophilicity, relative to $\mathrm{PHB}$. These engineered nanofibers also possessed superior mechanical properties relative to pristine PHB. ARPE-19 cells adhered well and actively proliferated on pec-PHB nanofibers, demonstrating the potential of this material as a scaffold for tissue engineering.

\section{MATERIALS AND METHODS}

Pectin (from apple), $\beta$-butyrolactone, tin(II) 2-ethylhexanoate, and 1,1,1,3,3,3-hexafluoro-2-propanol were purchased from Sigma-Aldrich. Solvents chloroform and $n$-hexane were of ACS grade and were purchased from J.T. Baker. All chemicals were used as received.

PHB was purified by dissolving in chloroform followed by filtration and subsequent precipitation in $n$-hexane before use. The absolute $M_{\mathrm{n}}$ and $M_{\mathrm{w}}$ of the purified PHB, characterized by miniDAWN multi-angle laser light scattering (Wyatt Technology) using $\mathrm{d} n / \mathrm{d} c=0.144$, were $6.0 \times 10^{4}$ and $7.1 \times 10^{4} \mathrm{~g}$ $\mathrm{mol}^{-1}$, respectively. The apparent $M_{\mathrm{n}}$ and $M_{\mathrm{w}}$ of the purified PHB, characterized by GPC (SEC RI detector) (Tosoh, Japan) with polymethylmethacrylate calibration standards, were $2.5 \times$ $10^{5}$ and $7.6 \times 10^{5} \mathrm{~g} \mathrm{~mol}^{-1}$, respectively.

4.1. Synthesis of pec-PHB Copolymer. pec-PHB was obtained by ROP using tin(II) 2-ethylhexanoate as a catalyst. The reaction mixture comprised pectin, $\beta$-butyrolactone, and tin(II) 2-ethylhexanoate (weight ratio, 1:5:0.05). The reaction mixture was stirred under an inert nitrogen atmosphere at 100 ${ }^{\circ} \mathrm{C}$ for $24 \mathrm{~h}$ and left to cool. Chloroform was added, and the resulting mixture was stirred overnight at $50{ }^{\circ} \mathrm{C}$. The mixture was left to cool and then centrifuged at $8000 \mathrm{rpm}$ for $5 \mathrm{~min}$. pec-PHB was obtained by precipitating the supernatant in $n$ hexane and drying under high vacuum at $40^{\circ} \mathrm{C}$.

4.2. Characterization of pec-PHB Copolymer. ${ }^{1} \mathrm{H}$ NMR spectra were recorded on a JEOL $500 \mathrm{MHz}$ NMR spectrometer (JEOL, Japan) at room temperature. The ${ }^{1} \mathrm{H}$ NMR measurements were carried out with an acquisition time of $4.37 \mathrm{~s}$, a pulse repetition time of $9.37 \mathrm{~s}$, and a $90^{\circ}$ pulse width. Measurements were performed with 16 scans, and chemical shifts were referred to the solvent peak $[\delta=4.79 \mathrm{ppm}$ for deuterium oxide $\left(\mathrm{D}_{2} \mathrm{O}\right)$ and $\delta=7.26 \mathrm{ppm}$ for deuterated chloroform $\left.\left(\mathrm{CDCl}_{3}\right)\right]$.

Fourier transform infrared (FTIR) spectra of potassium bromide $(\mathrm{KBr})$ pellet samples were recorded on a PerkinElmer Spectrum 2000 FTIR spectrophotometer (PerkinElmer); 16 scans were signal-averaged with a resolution of $4 \mathrm{~cm}^{-1}$ at room temperature. Pellet samples were prepared by mixing each sample with potassium bromide.

Thermogravimetric analysis (TGA) was performed using TGA Q500 (TA Instruments). Samples were heated from room temperature to $900{ }^{\circ} \mathrm{C}$ at a rate of $20{ }^{\circ} \mathrm{C} \mathrm{min}$ minder $^{-1}$ und continuous nitrogen purge with a flow rate of $40 \mathrm{~mL} \mathrm{~min}^{-1}$.

Differential scanning calorimetry (DSC) measurements were performed using DSC Q100 (TA Instruments) equipped with an autocool accessory and calibrated using indium. The following protocol was used for each sample: equilibrate at $-60{ }^{\circ} \mathrm{C}$ and isothermal for $5 \mathrm{~min}$, heating to $200{ }^{\circ} \mathrm{C}$ at $20^{\circ} \mathrm{C}$ $\mathrm{min}^{-1}$ and isothermal for $5 \mathrm{~min}$, cooling to $-60{ }^{\circ} \mathrm{C}$ at $20^{\circ} \mathrm{C}$ $\mathrm{min}^{-1}$ and isothermal for $5 \mathrm{~min}$, and finally reheating to $200{ }^{\circ} \mathrm{C}$ at $20{ }^{\circ} \mathrm{C} \mathrm{min}{ }^{-1}$. Data were collected from the second heating curve.

4.3. Electrospinning of PHB/pec-PHB Mixtures. A series of $\mathrm{PHB}$ and pec-PHB mixtures with various mass ratios were dissolved by stirring overnight in 1,1,1,3,3,3-hexafluoro-2propanol. The mass ratios of $\mathrm{PHB}$ and pec-PHB with a preset total concentration of $3 \% \mathrm{w} / \mathrm{v}$ were prepared as shown in Table 1. The solution was loaded in a $5 \mathrm{~mL}$ syringe with a blunt flattip 22-gauge needle and pumped out at $1 \mathrm{~mL} \mathrm{~h}^{-1}$ with $10 \mathrm{kV}$ of voltage applied on the needle. Fibers were electrospun on a collector wrapped with aluminum foil $(\approx 7.5 \mathrm{~cm}$ away from the needle tip). The fibers were left to dry in the fume hood at room temperature. PHB fibers were fabricated under the same parameters as the control.

4.4. Characterization of PHB/pec-PHB Fibers. Surface topographies of the fibers were characterized using JSM-6700F field emission scanning electron microscope (JEOL, Japan). Samples were sputter-coated with gold before imaging. Micrographs of each sample were obtained from random locations. The diameters of fibers were determined from 50 random measurements per image using ImageJ (National Institutes of Health).

The hydrophilicity of the fibers was evaluated by sessile water contact angle measurement using an NRL contact angle goniometer 100-00 (Ramé-Hart). Droplets of $5.00 \mu \mathrm{L}$ deionized water were sprinkled onto the fibers, and data were recorded after $10 \mathrm{~s}$. Three samples were used for each composition.

The mechanical properties of the fibers were measured by uniaxial tensile test using Instron 5943 (Instron) with $100 \mathrm{~N}$ load capacity at a rate of $10 \mathrm{~mm} \mathrm{~min}^{-1}$ at room temperature. The fibers were cut into rectangular strips of $5.0 \mathrm{~mm} \times 20.0$ $\mathrm{mm}$ for testing. The thickness of the samples was about 0.20 $\mathrm{mm}$, and the gauge length was $20.0 \mathrm{~mm}$. Three samples were prepared for each composition. Tensile strength, Young's modulus, and elongation at break were calculated on the basis of the stress-strain curve of each sample.

Thermal behavior of the fibers was investigated by TGA Q500 (TA Instruments) and DSC Q100 (TA Instruments) using the same procedure described above (refer to Section 2.2).

4.5. Statistical Analysis. Data were analyzed by one-way analysis of variance (ANOVA) with SPSS Statistic 21 software (IBM). The statistical significance was evaluated using Tukey post hoc test at $p<0.05$.

4.6. Biodegradability and Biocompatibility of PHB/ pec-PHB Fibers. 4.6.1. Degradation Studies. Fibers were incubated in phosphate-buffered saline (PBS) solution ( $\mathrm{pH}$ 7.4) at room temperature and lightly shaken at $150 \mathrm{rpm}$ for 2 weeks with PHB as the control. The PBS solution was changed every 2 days. Surface topographies of the fibers were characterized using JSM-6700F field emission scanning electron microscope (JEOL, Japan) on a weekly basis. Samples were sputter-coated with gold before imaging. Micrographs of each sample were obtained from random locations. The fibers were also incubated in PBS solution at pHs 7.4 and 12.0 at $37^{\circ} \mathrm{C}$ to identify the approximate period required for their complete solubilization. The PBS solution was changed every 2 days. 
4.6.2. CellTiter-Blue Assay. The fibers on round slides were UV-sterilized, inserted into 24-well microplates, and sterilized again. NIH/3T3 fibroblasts (ATCC CRL-1658) were cultured based on standard protocols provided by the American Tissue Culture Collection (ATCC). Cells grown in culture flasks were seeded onto 24-well microplates at a density of 5000 cells per well. After $72 \mathrm{~h}$, the resazurin (CellTiter-Blue Promega) cell viability assay was conducted according to the manufacturer's protocol. After $2 \mathrm{~h}$ of resazurin incubation, media extracts were transferred onto black 96-well microplates for reading at 560 $\mathrm{nm}$ excitation/590 $\mathrm{nm}$ emission. Tissue culture plastic was taken as the standard (viability $=1$ ), and all readings were normalized accordingly. Higher fluorescence readings indicate higher cell viability and better biocompatibility.

4.6.3. ARPE-19 Cell Culture. A commercially available human retinal pigmented epithelium cell line (ARPE-19, CRL-2302) was purchased from ATCC. Cells were first grown in Dulbecco's modified Eagle's medium and Ham's F12 (D-MEM/F12, 1:1) (Thermo Fisher Scientific) with 10\% fetal bovine serum until confluence. Thereafter, the cells were passaged by trypsin and seeded onto different fiber scaffolds in 24-well plates at a density of $1.00 \times 10^{4} \mathrm{cells} \mathrm{cm}^{-2}$ in the same media for in vitro experiments. Glass coverslips were used as controls. Cultures were incubated at $37{ }^{\circ} \mathrm{C}$ with $5 \% \mathrm{CO}_{2}$, and the medium was changed every 2 days.

ARPE-19 cell viability and proliferation were tested by 3(4,5-dimethylthiazol-2-yl)-2,5-diphenyltetrazolium bromide (MTT) assay (Molecular Probes), in reference to the manufacturer's instructions. In brief, three samples from each group of fibers were washed at different time points (days 1, 3, and 7 after seeding) and transferred to a new 24-well plate with fresh culture medium and incubated in MTT solution $(5 \mathrm{mg}$ $\left.\mathrm{mL}^{-1}\right)$ for $4 \mathrm{~h}$ at $37^{\circ} \mathrm{C}$. Dimethyl sulfoxide $(500 \mu \mathrm{L})$ was then added to each well plate to dissolve the formazan crystals. Absorbance was measured at $560 \mathrm{~nm}$ using a microplate reader (Infinite F200, Tecan, Switzerland). Data were analyzed by one-way ANOVA using GraphPad Prism software (GraphPad Software Inc.), and $p<0.05$ was regarded as statistically significant with a $95 \%$ confidence interval.

4.6.4. Immunocytochemistry. Immunocytochemistry was performed to certify the growth and distribution of ARPE-19 cells after $24 \mathrm{~h}$ of seeding. ARPE-19 cells on different fibers were incubated with rhodamine phalloidin (1:50 dilution, Molecular Probes) for $20 \mathrm{~min}$ at room temperature. The cells were air-dried and then mounted with VECTASHIELD Antifade Mounting Media with DAPI (Vector Laboratories). All images were taken at random locations with a Axio Imager M1 fluorescence microscope (Zeiss).

4.6.5. Morphology and Cell Attachment. The morphology and cell attachment of ARPE-19 cells on the scaffolds were observed by JEM-6330F scanning electron microscope (JEOL, Japan). The cells on scaffolds were fixed for $1 \mathrm{~h}$ using $3 \%$ glutaraldehyde at $24 \mathrm{~h}$ after cell seeding, followed by dehydration with hexamethyldisilazane. The samples were then air-dried overnight before observation. Micrographs of each sample were obtained at random locations.

\section{ASSOCIATED CONTENT}

\section{S Supporting Information}

The Supporting Information is available free of charge on the ACS Publications website at DOI: 10.1021/acsomega.7b01604.
NMR spectra, thermal analysis, and DSC curves of pectin $\mathrm{PHB}$ and the copolymer pec-PHB; SEM images $(7500 \times)$ of electrospun fibers without and with treatment (incubated in PBS solution $(\mathrm{pH} 7.4)$ at room temperature and lightly shaken at $150 \mathrm{rpm}$ for 2 weeks) for 7 days and 14 days; and cell viability of NIH/3T3 fibroblasts on $\mathrm{PHB}$ and pec-PHB nanofibers (PDF)

\section{AUTHOR INFORMATION}

\section{Corresponding Authors}

*E-mail: choo.wee.sim@monash.edu (W.S.C.).

*E-mail: dyoung1@usc.edu.au (D.J.Y.).

*E-mail: lohxj@imre.a-star.edu.sg (X.J.L.).

ORCID 웅

Benjamin Qi Yu Chan: 0000-0002-1383-0818

Xian Jun Loh: 0000-0001-8118-6502

\section{Notes}

The authors declare no competing financial interest.

\section{ACKNOWLEDGMENTS}

The authors acknowledge the funding and support from Monash University Malaysia, IMRE (A*STAR), IMCB (A*STAR), and National University of Singapore. The authors thank Dr. Zhang Zheng for assisting in the characterization of pec-PHB.

\section{REFERENCES}

(1) Chan, S. Y.; Choo, W. S.; Young, D. J.; Loh, X. J. Pectin as a rheology modifier: origin, structure, commercial production and rheology. Carbohydr. Polym. 2017, 161, 118-139.

(2) Chan, S. Y.; Choo, W. S.; Young, D. J.; Loh, X. J. Thixotropic Supramolecular Pectin-Poly(Ethylene Glycol) Methacrylate (PEGMA) Hydrogels. Polymers 2016, 8, 404.

(3) Chan, S.-Y.; Choo, W.-S. Effect of extraction conditions on the yield and chemical properties of pectin from cocoa husks. Food Chem. 2013, 141, 3752-3758.

(4) Kai, D.; Chua, Y. K.; Jiang, L.; Owh, C.; Chan, S. Y.; Loh, X. J. Dual functional anti-oxidant and SPF enhancing lignin-based copolymers as additives for personal and healthcare products. RSC Adv. 2016, 6, 86420-86427.

(5) Kai, D.; Ren, W.; Tian, L.; Chee, P. L.; Liu, Y.; Ramakrishna, S.; Loh, X. J. Engineering Poly(lactide)-Lignin Nanofibers with Antioxidant Activity for Biomedical Application. ACS Sustainable Chem. Eng. 2016, 4, 5268-5276.

(6) Kai, D.; Zhang, K.; Jiang, L.; Wong, H. Z.; Li, Z.; Zhang, Z.; Loh, X. J. Sustainable and Antioxidant Lignin-Polyester Copolymers and Nanofibers for Potential Healthcare Applications. ACS Sustainable Chem. Eng. 2017, 6016-6025.

(7) Yanamala, N.; Farcas, M. T.; Hatfield, M. K.; Kisin, E. R.; Kagan, V. E.; Geraci, C. L.; Shvedova, A. A. In Vivo Evaluation of the Pulmonary Toxicity of Cellulose Nanocrystals: A Renewable and Sustainable Nanomaterial of the Future. ACS Sustainable Chem. Eng. 2014, 2, 1691-1698.

(8) Dekamin, M. G.; Azimoshan, M.; Ramezani, L. Chitosan: a highly efficient renewable and recoverable bio-polymer catalyst for the expeditious synthesis of [small alpha]-amino nitriles and imines under mild conditions. Green Chem. 2013, 15, 811-820.

(9) Chan, S. Y.; Choo, W. S.; Young, D. J.; Loh, X. J. Pectin As a Rheology Modifier: Recent Reports on Its Origin, Structure, Commercial Production and Gelling Mechanism. In Polymers for Personal Care Products and Cosmetics; Loh, X. J., Ed.; The Royal Society of Chemistry, 2016; pp 205-226.

(10) Chan, B. Q. Y.; Low, Z. W. K.; Heng, S. J. W.; Chan, S. Y.; Owh, C.; Loh, X. J. Recent Advances in Shape Memory Soft Materials for 
Biomedical Applications. ACS Appl. Mater. Interfaces 2016, 8, 1007010087.

(11) Rosenbohm, C.; Lundt, I.; Christensen, T. I. E.; Young, N. G. Chemically methylated and reduced pectins: preparation, characterisation by $1 \mathrm{H}$ NMR spectroscopy, enzymatic degradation, and gelling properties. Carbohydr. Res. 2003, 338, 637-649.

(12) Leroux, J.; Langendorff, V.; Schick, G.; Vaishnav, V.; Mazoyer, J. Emulsion stabilizing properties of pectin. Food Hydrocolloids 2003, 17, $455-462$.

(13) Mishra, R. K.; Datt, M.; Pal, K.; Banthia, A. K. Preparation and characterization of amidated pectin based hydrogels for drug delivery system. J. Mater. Sci.: Mater. Med. 2008, 19, 2275-2280.

(14) Liang, R.-H.; Wang, L.-H.; Chen, J.; Liu, W.; Liu, C.-M. Alkylated pectin: synthesis, characterization, viscosity and emulsifying properties. Food Hydrocolloids 2015, 50, 65-73.

(15) Liu, C.-M.; Guo, X.-J.; Liang, R.-H.; Liu, W.; Chen, J. Alkylated pectin: molecular characterization, conformational change and gel property. Food Hydrocolloids 2017, 69, 341-349.

(16) Fan, L.; Cao, M.; Gao, S.; Wang, W.; Peng, K.; Tan, C.; Wen, F.; Tao, S.; Xie, W. Preparation and characterization of a quaternary ammonium derivative of pectin. Carbohydr. Polym. 2012, 88, 707-712.

(17) Sharma, R.; Ahuja, M. Thiolated pectin: synthesis, characterization and evaluation as a mucoadhesive polymer. Carbohydr. Polym. 2011, 85, 658-663.

(18) Bae, I. Y.; Joe, Y. N.; Rha, H. J.; Lee, S.; Yoo, S.-H.; Lee, H. G. Effect of sulfation on the physicochemical and biological properties of citrus pectins. Food Hydrocolloids 2009, 23, 1980-1983.

(19) Littoz, F.; McClements, D. J. Bio-mimetic approach to improving emulsion stability: cross-linking adsorbed beet pectin layers using laccase. Food Hydrocolloids 2008, 22, 1203-1211.

(20) Ogutu, F. O.; Mu, T.-H. Ultrasonic degradation of sweet potato pectin and its antioxidant activity. Ultrason. Sonochem. 2017, 38, 726734.

(21) Chen, J.; Liu, W.; Liu, C.-M.; Li, T.; Liang, R.-H.; Luo, S.-J. Pectin Modifications: A Review. Crit. Rev. Food Sci. Nutr. 2015, 55, 1684-1698.

(22) Choo, W. S.; Yap, J.; Chan, S. Antioxidant Properties of Two Varieties of Bitter Gourd (Momordica charantia) and the Effect of Blanching and Boiling on Them. Pertanika J. Trop. Agric. Sci. 2014, 37, 121-131.

(23) Ding, Y.; Li, W.; Müller, T.; Schubert, D. W.; Boccaccini, A. R.; Yao, Q.; Roether, J. A. Electrospun Polyhydroxybutyrate/Poly $(\varepsilon$ caprolactone)/58S Sol-Gel Bioactive Glass Hybrid Scaffolds with Highly Improved Osteogenic Potential for Bone Tissue Engineering. ACS Appl. Mater. Interfaces 2016, 8, 17098-17108.

(24) Venault, A.; Subarja, A.; Chang, Y. Zwitterionic Polyhydroxybutyrate Electrospun Fibrous Membranes with a Compromise of Bioinert Control and Tissue-Cell Growth. Langmuir 2017, 33, 24602471.

(25) Wagner, A.; Poursorkhabi, V.; Mohanty, A. K.; Misra, M. Analysis of Porous Electrospun Fibers from Poly(1-lactic acid)/Poly(3hydroxybutyrate-co-3-hydroxyvalerate) Blends. ACS Sustainable Chem. Eng. 2014, 2, 1976-1982.

(26) Nicosia, A.; Gieparda, W.; Foksowicz-Flaczyk, J.; Walentowska, J.; Wesołek, D.; Vazquez, B.; Prodi, F.; Belosi, F. Air filtration and antimicrobial capabilities of electrospun PLA/PHB containing ionic liquid. Sep. Purif. Technol. 2015, 154, 154-160.

(27) Fabra, M. J.; Lopez-Rubio, A.; Lagaron, J. M. Effect of the filmprocessing conditions, relative humidity and ageing on wheat gluten films coated with electrospun polyhydroxyalkanoate. Food Hydrocolloids 2015, 44, 292-299.

(28) Lao, H.-K.; Renard, E.; Linossier, I.; Langlois, V.; Vallée-Rehel, K. Modification of Poly(3-hydroxybutyrate-co-3-hydroxyvalerate) Film by Chemical Graft Copolymerization. Biomacromolecules 2007, 8, $416-423$.

(29) Guo, J.; Zhang, Q.; Cai, Z.; Zhao, K. Preparation and dye filtration property of electrospun polyhydroxybutyrate-calcium alginate/carbon nanotubes composite nanofibrous filtration membrane. Sep. Purif. Technol. 2016, 161, 69-79.
(30) Goonoo, N.; Khanbabaee, B.; Steuber, M.; Bhaw-Luximon, A.; Jonas, U.; Pietsch, U.; Jhurry, D.; Schönherr, H. $\kappa$-Carrageenan Enhances the Biomineralization and Osteogenic Differentiation of Electrospun Polyhydroxybutyrate and Polyhydroxybutyrate Valerate Fibers. Biomacromolecules 2017, 18, 1563-1573.

(31) Zhijiang, C.; Yi, X.; Haizheng, Y.; Jia, J.; Liu, Y. Poly(hydroxybutyrate)/cellulose acetate blend nanofiber scaffolds: preparation, characterization and cytocompatibility. Mater. Sci. Eng., C 2016, 58, 757-767.

(32) Arrieta, M. P.; López, J.; López, D.; Kenny, J. M.; Peponi, L. Effect of chitosan and catechin addition on the structural, thermal, mechanical and disintegration properties of plasticized electrospun PLA-PHB biocomposites. Polym. Degrad. Stab. 2016, 132, 145-156.

(33) Lopez-Sanchez, P.; Martinez-Sanz, M.; Bonilla, M. R.; Wang, D.; Walsh, C. T.; Gilbert, E. P.; Stokes, J. R.; Gidley, M. J. Pectin impacts cellulose fibre architecture and hydrogel mechanics in the absence of calcium. Carbohydr. Polym. 2016, 153, 236-245.

(34) Cosgrove, D. J. Plant cell wall extensibility: connecting plant cell growth with cell wall structure, mechanics, and the action of wallmodifying enzymes. J. Exp. Bot. 2016, 67, 463-476.

(35) Hocq, L.; Pelloux, J.; Lefebvre, V. Connecting Homogalacturonan-Type Pectin Remodeling to Acid Growth. Trends Plant Sci. 2017, 22, 20-29.

(36) Agarwal, S.; Wendorff, J. H.; Greiner, A. Use of electrospinning technique for biomedical applications. Polymer 2008, 49, 5603-5621.

(37) Sun, B.; Long, Y. Z.; Zhang, H. D.; Li, M. M.; Duvail, J. L.; Jiang, X. Y.; Yin, H. L. Advances in three-dimensional nanofibrous macrostructures via electrospinning. Prog. Polym. Sci. 2014, 39, 862890.

(38) Kai, D.; Liow, S. S.; Loh, X. J. Biodegradable polymers for electrospinning: towards biomedical applications. Mater. Sci. Eng., C 2014, 45, 659-670.

(39) Ang, J. Y.; Chan, B. Q. Y.; Kai, D.; Loh, X. J. Engineering Porous Water-Responsive Poly(PEG/PCL/PDMS Urethane) Shape Memory Polymers. Macromol. Mater. Eng. 2017, No. 1700174.

(40) Chan, B. Q. Y.; Heng, S. J. W.; Liow, S. S.; Zhang, K.; Loh, X. J. Dual-responsive hybrid thermoplastic shape memory polyurethane. Mater. Chem. Front. 2017, 1, 767-779.

(41) Chan, B. Q. Y.; Liow, S. S.; Loh, X. J. Organic-inorganic shape memory thermoplastic polyurethane based on polycaprolactone and polydimethylsiloxane. RSC Adv. 2016, 6, 34946-34954.

(42) Cai, P.; Layani, M.; Leow, W. R.; Amini, S.; Liu, Z.; Qi, D.; Hu, B.; Wu, Y.-L.; Miserez, A.; Magdassi, S.; Chen, X. Bio-Inspired Mechanotactic Hybrids for Orchestrating Traction-Mediated Epithelial Migration. Adv. Mater. 2016, 28, 3102-3110.

(43) Cai, P.; Leow, W. R.; Wang, X.; Wu, Y.-L.; Chen, X. Programmable Nano-Bio Interfaces for Functional Biointegrated Devices. Adv. Mater. 2017, 29, No. 1605529.

(44) Kai, D.; Prabhakaran, M. P.; Chan, B. Q. Y.; Liow, S. S.; Ramakrishna, S.; Xu, F.; Loh, X. J. Elastic poly( $\varepsilon$-caprolactone)polydimethylsiloxane copolymer fibers with shape memory effect for bone tissue engineering. Biomed. Mater. 2016, 11, No. 015007.

(45) Kai, D.; Tan, M. J.; Prabhakaran, M. P.; Chan, B. Q. Y.; Liow, S. S.; Ramakrishna, S.; Loh, X. J. Biocompatible electrically conductive nanofibers from inorganic-organic shape memory polymers. Colloids Surf., B 2016, 148, 557-565.

(46) Yao, J.; Tao, S. L.; Young, M. J. Synthetic Polymer Scaffolds for Stem Cell Transplantation in Retinal Tissue Engineering. Polymers 2011, 3, 899.

(47) Chen, H.; Fan, X.; Xia, J.; Chen, P.; Zhou, X.; Huang, J.; Yu, J.; $\mathrm{Gu}, \mathrm{P}$. Electrospun chitosan-graft-poly ( $\varepsilon$-caprolactone $) / \operatorname{poly}(\varepsilon-$ caprolactone) nanofibrous scaffolds for retinal tissue engineering. Int. J. Nanomed. 2011, 6, 453-461.

(48) Warnke, P. H.; Alamein, M.; Skabo, S.; Stephens, S.; Bourke, R.; Heiner, P.; Liu, Q. Primordium of an artificial Bruch's membrane made of nanofibers for engineering of retinal pigment epithelium cell monolayers. Acta Biomater. 2013, 9, 9414-9422.

(49) Karamichos, D. Ocular Tissue Engineering: Current and Future Directions. J. Funct. Biomater. 2015, 6, 77-80. 
(50) White, C. E.; Olabisi, R. M. Scaffolds for retinal pigment epithelial cell transplantation in age-related macular degeneration. $J$. Tissue Eng. 2017, 8, No. 2041731417720841.

(51) Guo, B.; Ma, P. X. Synthetic biodegradable functional polymers for tissue engineering: a brief review. Sci. China: Chem. 2014, 57, 490500.

(52) Harabagiu, V.; Simionescu, B. C.; Pinteala, M.; Merrienne, C.; Mahuteau, J.; Guégan, P.; Cheradame, H. Synthesis and characterization of persilylated cyclodextrins. Carbohydr. Polym. 2004, 56, 301311.

(53) Gnanasambandam, R.; Proctor, A. Determination of pectin degree of esterification by diffuse reflectance Fourier transform infrared spectroscopy. Food Chem. 2000, 68, 327-332.

(54) Synytsya, A.; Čopíková, J.; Matějka, P.; Machovič, V. Fourier transform Raman and infrared spectroscopy of pectins. Carbohydr. Polym. 2003, 54, 97-106.

(55) Chatjigakis, A. K.; Pappas, C.; Proxenia, N.; Kalantzi, O.; Rodis, P.; Polissiou, M. FT-IR spectroscopic determination of the degree of esterification of cell wall pectins from stored peaches and correlation to textural changes. Carbohydr. Polym. 1998, 37, 395-408.

(56) Bayar1, S.; Severcan, F. FTIR study of biodegradable biopolymers: $\mathrm{P}(3 \mathrm{HB}), \mathrm{P}(3 \mathrm{HB}-\mathrm{co}-4 \mathrm{HB})$ and $\mathrm{P}(3 \mathrm{HB}-\mathrm{co}-3 \mathrm{HV})$. J. Mol. Struct. 2005, 744-747, 529-534.

(57) Randriamahefa, S.; Renard, E.; Guérin, P.; Langlois, V. Fourier Transform Infrared Spectroscopy for Screening and Quantifying Production of PHAs by Pseudomonas Grown on Sodium Octanoate. Biomacromolecules 2003, 4, 1092-1097.

(58) Mangiacapra, P.; Gorrasi, G.; Sorrentino, A.; Vittoria, V. Biodegradable nanocomposites obtained by ball milling of pectin and montmorillonites. Carbohydr. Polym. 2006, 64, 516-523.

(59) Waymack, B. E.; Belote, J. L.; Baliga, V. L.; Hajaligol, M. R. Effects of metal salts on char oxidation in pectins/uronic acids and other acid derivative carbohydrates. Fuel 2004, 83, 1505-1518.

(60) Adamus, G.; Sikorska, W.; Janeczek, H.; Kwiecień, M.; Sobota, M.; Kowalczuk, M. Novel block copolymers of atactic PHB with natural PHA for cardiovascular engineering: synthesis and characterization. Eur. Polym. J. 2012, 48, 621-631.

(61) Shi, X.; Zhang, G.; Phuong, T.; Lazzeri, A. Synergistic Effects of Nucleating Agents and Plasticizers on the Crystallization Behavior of Poly(lactic acid). Molecules 2015, 20, 1579.

(62) Barnes, C. P.; Sell, S. A.; Boland, E. D.; Simpson, D. G.; Bowlin, G. L. Nanofiber technology: designing the next generation of tissue engineering scaffolds. Adv. Drug Delivery Rev. 2007, 59, 1413-1433.

(63) Rahul, V. G.; Nair, P. D. Biomaterials and Designs Supporting Cartilage Regeneration. In Biomaterials and Nanotechnology for Tissue Engineering; Swaminathan, S., Maheswari, K. A., Anuradha, S., Eds.; CRC Press, 2016; pp 93-103.

(64) Qiu, J.; Xing, C.; Cao, X.; Wang, H.; Wang, L.; Zhao, L.; Li, Y. Miscibility and Double Glass Transition Temperature Depression of Poly(l-lactic acid) (PLLA)/Poly(oxymethylene) (POM) Blends. Macromolecules 2013, 46, 5806-5814.

(65) Di Lorenzo, M. L.; Gazzano, M.; Righetti, M. C. The Role of the Rigid Amorphous Fraction on Cold Crystallization of Poly(3hydroxybutyrate). Macromolecules 2012, 45, 5684-5691.

(66) Yao, J.; Bastiaansen, C.; Peijs, T. High Strength and High Modulus Electrospun Nanofibers. Fibers 2014, 2, 158.

(67) Gunaratne, L. M. W. K.; Shanks, R. A. Miscibility, melting, and crystallization behavior of poly(hydroxybutyrate) and poly(D,L-lactic acid) blends. Polym. Eng. Sci. 2008, 48, 1683-1692.

(68) Anbukarasu, P.; Sauvageau, D.; Elias, A. Tuning the properties of polyhydroxybutyrate films using acetic acid via solvent casting. Sci. Rep. 2015, 5, No. 17884.

(69) Barham, P. J.; Keller, A.; Otun, E. L.; Holmes, P. A. Crystallization and morphology of a bacterial thermoplastic: poly-3hydroxybutyrate. J. Mater. Sci. 1984, 19, 2781-2794.

(70) Kouhi, M.; Prabhakaran, M. P.; Shamanian, M.; Fathi, M.; Morshed, M.; Ramakrishna, S. Electrospun PHBV nanofibers containing $\mathrm{HA}$ and bredigite nanoparticles: fabrication, character- ization and evaluation of mechanical properties and bioactivity. Compos. Sci. Technol. 2015, 121, 115-122.

(71) Fronk, A. H.; Vargis, E. Methods for culturing retinal pigment epithelial cells: a review of current protocols and future recommendations. J. Tissue Eng. 2016, 7, No. 2041731416650838.

(72) Alexander, P.; Thomson, H. A. J.; Luff, A. J.; Lotery, A. J. Retinal pigment epithelium transplantation: concepts, challenges, and future prospects. Eye 2015, 29, 992-1002.

(73) Salero, E.; Blenkinsop; Timothy, A.; Corneo, B.; Harris, A.; Rabin, D.; Stern; Jeffrey, H.; Temple, S. Adult Human RPE Can Be Activated into a Multipotent Stem Cell that Produces Mesenchymal Derivatives. Cell Stem Cell 2012, 10, 88-95.

(74) Samuel, W.; Jaworski, C.; Postnikova, O. A.; Kutty, R. K.; Duncan, T.; Tan, L. X.; Poliakov, E.; Lakkaraju, A.; Redmond, T. M. Appropriately differentiated ARPE-19 cells regain phenotype and gene expression profiles similar to those of native RPE cells. Mol. Vision 2017, 23, 60-89.

(75) He, L.; Liao, S.; Quan, D.; Ma, K.; Chan, C.; Ramakrishna, S.; $\mathrm{Lu}$, J. Synergistic effects of electrospun PLLA fiber dimension and pattern on neonatal mouse cerebellum C17.2 stem cells. Acta Biomater. 2010, 6, 2960-2969.

(76) Smith, A. M.; Paxton, J. Z.; Hung, Y.-P.; Hadley, M. J.; Bowen, J.; Williams, R. L.; Grover, L. M. Nanoscale crystallinity modulates cell proliferation on plasma sprayed surfaces. Mater. Sci. Eng., C 2015, 48, 5-10.

(77) Areias, A. C.; Ribeiro, C.; Sencadas, V.; Garcia-Giralt, N.; DiezPerez, A.; Gomez Ribelles, J. L.; Lanceros-Mendez, S. Influence of crystallinity and fiber orientation on hydrophobicity and biological response of poly(l-lactide) electrospun mats. Soft Matter 2012, 8, $5818-5825$. 